\title{
Shape of Aquatic Animals and Their Swimming Efficiency
}

\author{
I. Nesteruk, ${ }^{1}$ G. Passoni, ${ }^{2}$ and A. Redaelli ${ }^{2}$ \\ ${ }^{1}$ Institute of Hydromechanics, National Academy of Sciences of Ukraine, Zhelyabova 8/4, Kyiv 03680, Ukraine \\ ${ }^{2}$ Dipartimento di Elettronica, Informazione e Bioingegneria, Politecnico di Milano, Piazza L. da Vinci, 32-20133 Milan, Italy
}

Correspondence should be addressed to I. Nesteruk; inesteruk@yahoo.com

Received 2 December 2013; Accepted 4 January 2014; Published 25 February 2014

Academic Editor: Jakov Dulčić

Copyright (C) 2014 I. Nesteruk et al. This is an open access article distributed under the Creative Commons Attribution License, which permits unrestricted use, distribution, and reproduction in any medium, provided the original work is properly cited.

\begin{abstract}
The best swimmers have a streamlined shape that ensures an attached flow pattern and a laminar boundary layer at rather large values of the Reynolds number. Simple expressions may be obtained for the volumetric drag coefficient of an ideal body of revolution under laminar unseparated flow conditions together with estimations of a critical value of the Reynolds number. A measure, the capacity-efficiency factor, calculated for different organisms and underwater vehicles, shows that information about animal shapes and locomotion is of utmost biological interest and could be useful to improve robot fish and underwater vehicles as well.
\end{abstract}

\section{Introduction}

From the hydromechanical point of view fish swimming is a very complicated unsteady phenomenon. A description of the diversity of fish locomotion and a classification of swimming modes, categories, and styles can be found in Blake [1]. Moreover, recent interest in robot fish requires answering questions about optimal shape and the power necessary for fish locomotion. This study focuses on the most simple estimations of fish drag and power requirements during quasisteady motion when changes in body shape can be neglected. This approach would not be very reliable in the case of anguilliform propulsion, but it is acceptable for the carangiand thunniforms of the best swimmers (see [2-4]).

The best swimmers must have a small drag coefficient:

$$
C_{V}=\frac{2 X}{\rho U_{\infty}^{2} V^{2 / 3}}
$$

to achieve high underwater velocity. In this case a body of volume $V$ moving at a constant speed $U_{\infty}$ in a fluid with density $\rho$ exhibits low $\operatorname{drag} X$. Owing to the huge difference in water and air densities, an underwater body has approximately 800 times larger drag than the same body moving in air at the same velocity, since, at equal Reynolds numbers, the drag coefficients are approximately equal. For large Reynolds number the boundary layer thickness can be neglected and fluid outside the thin layer can be treated as ideal and incompressible. For underwater swimming the wave drag, important for ships or animals moving on the water surface, is negligible.

The total drag can be divided into pressure and friction components. The pressure drag can be reduced almost to zero when the boundary layer does not separate from the body surface. In this case the d'Alembert paradox applies; that is, a closed rigid body in unbounded flow of ideal incompressible fluid has zero drag (see, e.g., [5]). Experiments with animals that are good swimmers (like dolphins) have shown that during gliding (inertial movement without manoeuvring and shape change) they exhibit unseparated flow pattern (e.g., $[6,7])$. Attached flow has also been observed around the special-shaped body UA-2 [8]. Its UA-2c version is shown in Figure 1.

To reduce friction, a laminar boundary layer must be maintained as large as possible over the wetted surface. Therefore, an ideal good swimmer must have an unseparated laminar boundary layer over its whole surface. In this paper the drag coefficient and the capacity characteristics of a corresponding slender body of revolution (with a small ratio of maximum diameter $D$ to length $L$ ) have been calculated for different animals, human athletes, and submarines in order to compare them in terms of swimming efficiency. 

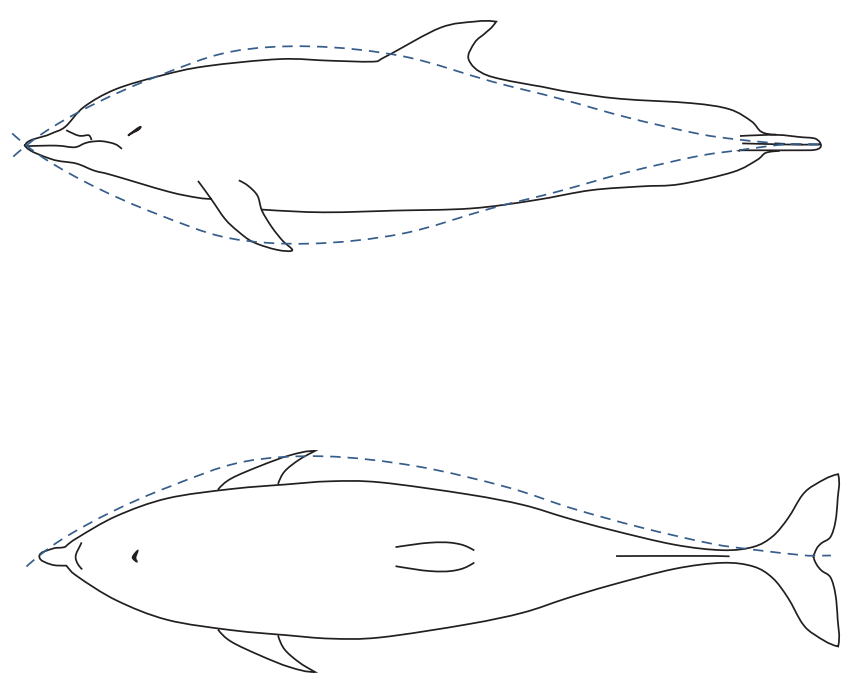

FIGURE 1: Comparison of the shape UA-2c with the body of a bottlenose dolphin [9].

\section{Materials and Methods}

2.1. Frictional Drag on a Slender Body of Revolution. To estimate laminar frictional drag on a slender body of revolution, the Mangler-Stepanov transformations (see, e.g., [5]), which reduce the rotationally symmetric boundary layer equations to a two-dimensional case, can be used. The following relations between coordinates $x, y$ for the rotationally symmetric boundary layer (shown in Figure 2) and the corresponding two-dimensional coordinates $\bar{x}, \bar{y}$ are valid (coordinates are dimensionless based on the body length):

$$
\bar{x}=\int_{0}^{x} R^{2}(\xi) d \xi, \quad \bar{y}=R(x) y,
$$

where $R(x)$ is the dimensionless radius of the rotationally symmetric body based on its length $L$. The flow velocity at the outer edge of the boundary layer, the displacement thickness, and the skin-friction coefficient are related as follows (see, e.g., [5]):

$$
\bar{U}=U, \quad \delta^{*}=\frac{\bar{\delta}^{*}}{R(x)}, \quad \tau_{w}=\bar{\tau}_{w} R(x) .
$$

All the values in (3) are dimensionless, based on ambient flow velocity $U_{\infty}$, body length $L$, and $0.5 \rho U_{\infty}^{2}$, respectively. These equations are valid for an arbitrary rotationally symmetric body provided that the thickness of the boundary layer is small in comparison with the radius; that is, the flow is unseparated. For a slender body, the coordinate $x$ can be calculated along the body's axis and the velocity $U$ can be supposed to be equal to unity, neglecting the thickness of the boundary layer and the pressure distribution peculiarities (see, e.g., [10]). From the first equation of (3) the value of $U$ will also be equal to unity; that is, the rotationally symmetric boundary layer on a slender body can be reduced to the flat plate one [11]. According to the Blasius expression, the equality holds $\bar{\tau}_{w}=0.664(\bar{x})^{-1 / 2} R_{L}^{-1 / 2}$ for a laminar flow,

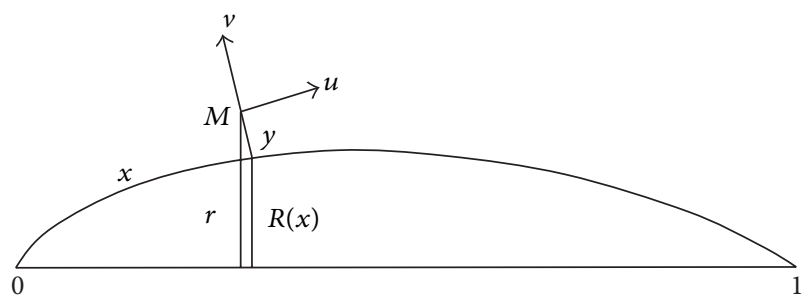

FIGURE 2: Boundary layer on a slender rotationally symmetric body.

where the Reynolds number $R_{L}=U_{\infty} L / v$ and $v$ is the kinematic viscosity (see, e.g., [5]). Introducing the variable $x$, using (2) and (3), the laminar skin-friction drag coefficients of a slender rotationally symmetric body may be obtained as

$$
\begin{aligned}
C_{L} & =\frac{2 X}{\rho U_{\infty}^{2} L^{2}}=2 \pi \int_{0}^{1} R(x) \tau_{w}(x) d x \\
& =\frac{4.172}{\sqrt{R_{L}}} \int_{0}^{1} R^{2}(x)\left[\int_{0}^{x} R^{2}(\xi) d \xi\right]^{-1 / 2} d x \\
& =8.344 \sqrt{\frac{V}{\pi L^{3} R_{L}}}
\end{aligned}
$$

and using (1),

$$
C_{V}=\frac{4.708}{\sqrt{R_{V}}}
$$

where the volumetric Reynolds number $R_{V}=U_{\infty} V^{1 / 3} / \nu$.

Note that the volumetric frictional drag coefficient $C_{V}$ does not depend on the slender body shape, provided its volume remains constant (see also [11]). Anyway, this is valid for laminar attached boundary layer and at limited $R_{V}$ only. In the next section the critical value of the Reynolds number will be calculated. But in any case (5) is a reliable estimate for the minimum possible drag on a rigid body of revolution.

2.2. Critical Values of the Reynolds Number. The laminar-toturbulent flow transition in the boundary layer influences the skin-friction drag and depends on many parameters such as pressure gradient, surface roughness, and pulsations in the ambient flow (e.g., [5]). Nevertheless, according to the Tollmien-Schlichting-Lin theory (e.g., [12]), the boundary layer on a flat plate remains laminar for any frequencies of disturbances if

$$
R^{*}=\frac{\bar{U} \bar{\delta}^{*}}{v}<420 .
$$

This inequality, taking into account the Blasius expression for displacement thickness (e.g., [5]) $\bar{\delta}^{*}=1.721(\bar{x})^{1 / 2} R_{L}^{-1 / 2}$, can be rewritten as follows:

$$
\sqrt{\bar{x} R_{L}}<244.04
$$

In the previous section it has been shown that the boundary layer around a slender body of revolution can be reduced to 


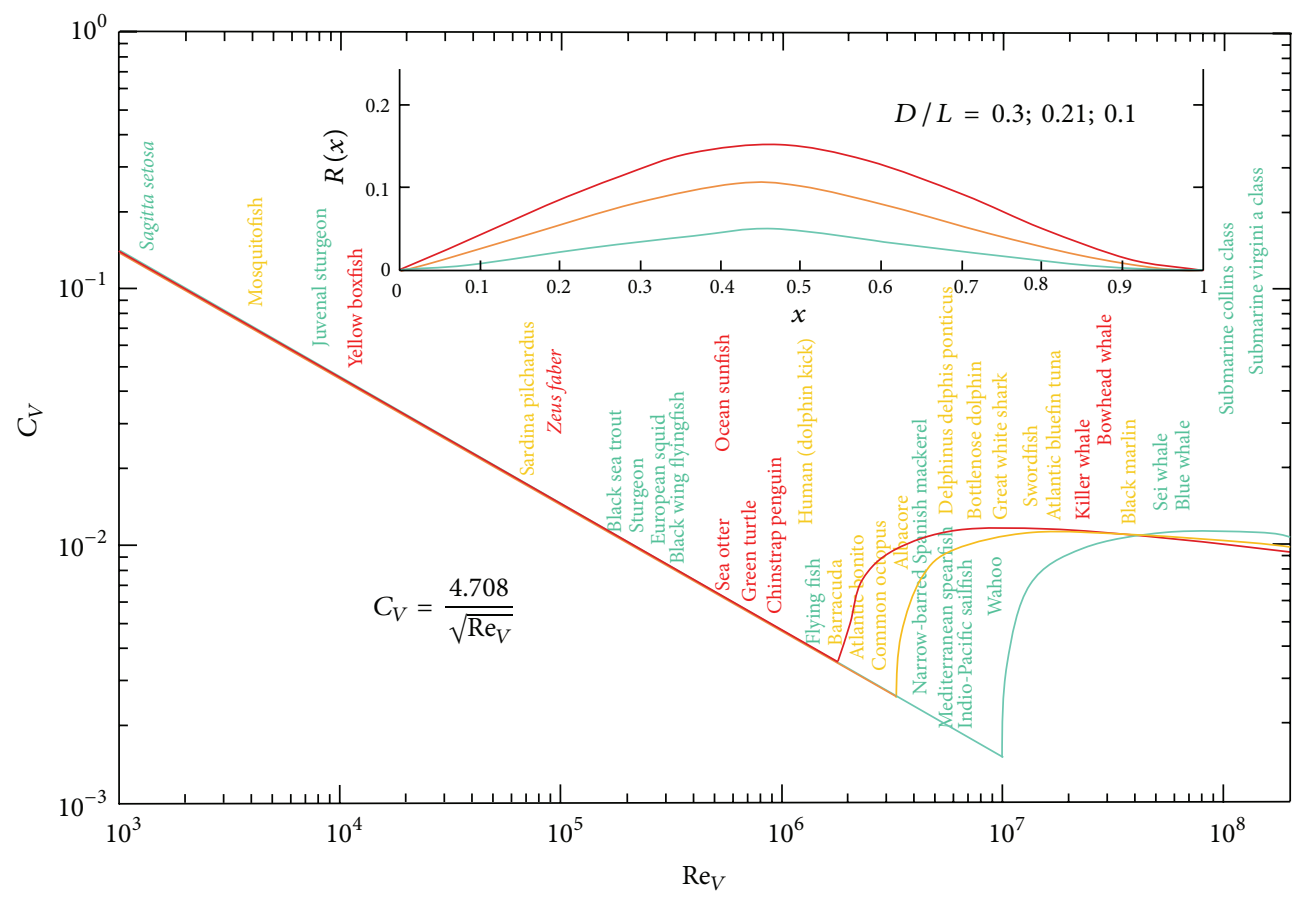

FIgURE 3: Minimal drag coefficients for different animals and vehicles. Typical shapes at different values of the thickness ratio $D / L$.

that on a plate with the use of the Mangler-Stepanov transformation. Given (2) and (7), the condition for the axisymmetrical boundary layer to remain laminar can be written as follows [13]:

$$
R_{L} \int_{0}^{x} R^{2}(\xi) d \xi<59558
$$

If the boundary layer remains laminar over the entire surface, the integral in (8) can be substituted by

$$
\int_{0}^{1} R^{2}(\xi) d \xi=\frac{V}{\pi L^{3}}
$$

Thus,

$$
R_{L}<\frac{59558 \pi L^{3}}{V} \text { or } \quad R_{V}<\frac{59558 \pi L^{2}}{V^{2 / 3}} .
$$

To calculate the critical values of the Reynolds numbers $R_{L}^{*}$ and $R_{V}^{*}$, corresponding to the right-hand parts of the inequalities (10), information about the body shape is necessary. Supposing the optimal body shape to be close to that of the dolphin or UA-2c, the ratio $V / L^{3}$ can be determined directly after calculating the corresponding shape with the use of the method proposed in Nesteruk [8]. Typical shapes for various ratios $D / L$ are shown in Figure 3. The ratio $V / L^{3}$ can be calculated from the following approximate expression:

$$
\frac{V}{L^{3}}=k\left(\frac{D}{L}\right)^{2},
$$

with the values of parameter $k=0.2574 ; 0.2998 ; 0.3335$ for $D / L=0.1 ; 0.21 ; 0.3$, respectively. To simplify the calculations, the average value $k=0.295$ is used.
Both the forebody and the tail of the shape corresponding to the smallest thickness ratio $D / L=0.1$ are concave, while for less slender bodies $(D / L=0.21$ and $D / L=0.3)$ only the tail is concave (see Figure 3). Some fast-swimming fish have a concave forebody too (e.g., the Mediterranean spearfish Tetrapturus belone, Indo-Pacific sailfish Istiophorus platypterus, black marlin Makaira indica, or swordfish Xiphias gladius).

With the use of (10) and (11) the critical Reynolds number can be estimated as follows:

$$
R_{L}^{*} \approx 6.3 \cdot 10^{5} \frac{L^{2}}{D^{2}} \quad \text { or } \quad R_{V}^{*} \approx 4.2 \cdot 10^{5} \frac{L^{4 / 3}}{D^{4 / 3}} .
$$

Equations (12) show that the boundary layer remains laminar on slender bodies of revolution at rather large Reynolds numbers and the critical value of the Reynolds number increases with the diminishing of the thickness ratio $D / L$.

2.3. Power Requirements for Swimming. The power balance for steady swimming at maximum velocity $U_{m}$, when the thrust is equal to the drag $X$, can be written as follows:

$$
q m \eta=U_{m} X=U_{m} C_{V} \rho \frac{U_{m}^{2}}{2} V^{2 / 3},
$$

where $q$ is the physiological maximum of the available animal power per unit mass, $m$ is that mass, and $0<\eta<1$ is the propulsion efficiency, which takes into account the fin drag. Assuming a neutrally buoyant animal $(m=\rho V$, in the case of negatively buoyant animals the difference between weight and buoyancy does not exceed 10\%, e.g., [14], and can be 
neglected), the capacity-efficiency factor $q \eta$ can be estimated as

$$
q \eta=\frac{U_{m}^{3} C_{V}}{2 V^{1 / 3}} .
$$

If the animal body shape is close to the slender rotationally symmetric one and ensures an unseparated flow pattern, then for a purely laminar boundary layer, (5) and (14) yield

$$
C_{E}=(q \eta)_{\min }=2.354 \frac{U_{m}^{3}}{\sqrt{R_{V}} V^{1 / 3}}=2.354 \frac{U_{m}^{2.5} \sqrt{\nu}}{\sqrt{V}} .
$$

In dimensionless form (15) can be written as follows:

$$
c_{E}=\frac{C_{E}}{v^{1 / 2} g^{4 / 3}}=2.354 \frac{U_{m}^{2.5} v^{1 / 6} \sqrt{\rho}}{g^{4 / 3} \sqrt{m}} .
$$

\section{Results}

3.1. Which Shape Is Better? When designing robot fish or other underwater vehicles, the goal is to minimize the drag for a given volume and a prescribed velocity range. To solve this problem, the minimum volumetric drag coefficient $C_{V}$ for the hull (the main part of the body) must be achieved at the given volumetric Reynolds number $R_{V}$. Thus, the question arises: what kind of shape must be chosen?

Since for laminar attached flow on a slender body of revolution $C_{V}$ is independent of the shape (see (5)), the hull shape may be arbitrary provided it ensures a laminar attached flow. For example, any shape shown in Figure 3 can be used at the corresponding subcritical Reynolds number range. If $R_{V}>R_{V}^{*}$, the tail part of the hull has a turbulent boundary layer and the optimal shape depends on the thickness ratio $D / L$ and tail shape peculiarities.

It is rather difficult to calculate the frictional drag for supercritical Reynolds numbers, especially in the laminar-toturbulent transition region. Expression (5) has been used for the laminar forebody and the flat plate concept (e.g., [15]) for the turbulent tail. The results are represented in Figure 3. For subcritical Reynolds numbers the universal straight line corresponds to (5) in logarithmic coordinates. For $R_{V}>R_{V}^{*}$ as shown in Figure 3 this line bifurcates into different colour lines corresponding to the shapes with different values of the thickness ratio $D / L=0.1 ; 0.21 ; 0.3$ (green, yellow, and red lines, resp.).

For different animals the typical Reynolds numbers are shown in Figure 3. For comparison, the cases of a human sportsman (during underwater dolphin-kick swimming at velocity $2.7 \mathrm{~m} / \mathrm{s}$ ) and two different submarines are also presented in Figure 3. All names shown in green correspond to the values of the thickness ratio $D / L \leq 0.15$, in yellow $0.15<D / L \leq 0.25$, and in red $D / L>0.25$.

To emphasize the fact that the theoretical curves in Figure 3 show the minimal possible values of the drag, all names are written over the corresponding lines. For example, the real total drag coefficients for submarines (based on their mass, maximum underwater velocity, capacity, propeller efficiency 0.85 , and $v=1.3 \cdot 10^{-6} \mathrm{~m}^{2} / \mathrm{s}$; also shown in
Figure 3 by green markers "+") are $3-5$ times greater than the minimum theoretical values shown by the green line. This fact can be explained by the presence of separation on the submarines' hulls. Small organisms (e.g., mosquitofish) have greater values of $C_{V}$ than the submarines (see Figure 3 ).

The minimum possible values of $0.0015<C_{V}<0.002$ correspond to animals with very slender bodies (e.g., narrowbarred Spanish mackerel Scomberomorus commerson, wahoo Acanthocybium solandri, Mediterranean spearfish Tetrapturus belone, Indo-Pacific sailfish Istiophorus platypterus, and saltwater crocodile Crocodylus porosus) and are located at the subcritical Reynolds number range $6 \cdot 10^{6}<R_{V}<10^{7}$. For plumper animals (e.g., dolphins, sharks) the same $R_{V}$ range is already supercritical and greater values of $C_{V}$ are expected. Whales and some fast-swimming fish (e.g., swordfish Xiphias gladius, black marlin Makaira indica) swim at supercritical Reynolds numbers.

3.2. Capacity-Efficiency Factor. Equation (15) allows estimating the capacity-efficiency factor for different animals and vehicles with the use of their data for maximum speed, volume, and viscosity of water. Large values of $C_{E}$ correspond to the better swimmers (i.e., the animals that can produce more energy per unit time and per unit mass and use it effectively for locomotion). Smaller values of this factor correspond to animals or vehicles that have a large drag (greater than the theoretical minimum (5)) and do not need to (or cannot) use a lot of their energy for fast-swimming and/or cannot use their energy in proper way (e.g., due to the small efficiency $\eta)$.

Examples of calculation of the capacity-efficiency factor are presented in Figure 4 and in Tables 1 and 2. In Table 1 the data from Aleyev [6] (crosses in Figure 4) have been used. In Table 2 the different data about the animals mass and maximal velocity have been used for calculations (circles in Figure 4). Different colours of points correspond to the different values of the thickness ratio $D / L$, as mentioned in the previous section.

Unfortunately, for the majority of the data points, it is very difficult to determine the relevant value of the viscosity of water, which varies from $v \approx 1.8 \cdot 10^{-6} \mathrm{~m}^{2} / \mathrm{s}$ at $0^{\circ} \mathrm{C}$ to $v=$ $0.66 \cdot 10^{-6} \mathrm{~m}^{2} / \mathrm{s}$ at $40^{\circ} \mathrm{C}$. In Aleyev [6] only data about animal length, the ratio $D / L$, and $R_{L}$ are available. To calculate the velocities the average value $v=1.3 \cdot 10^{-6} \mathrm{~m}^{2} / \mathrm{s}$ was used. The volume was estimated with the use of (11). Inaccuracy in the maximum velocity, the mass, and viscosity data is a reason for discrepancies in $C_{E}$ values obtained for the same animals in Tables 1 and 2.

\section{Discussion}

4.1. Comparison with the Literature. Since the experimental drag data for live animals are very limited, expression (5) is here related only to rigid bodies of revolution. The body Dolphin was manufactured and tested by North American Aviation in 1967-1968 (see [16]). The profile NACA-66 was chosen for the shape of this body of revolution; its parameters were $L / D=3.33 ; D=0.48 \mathrm{~m} ; L=1.6 \mathrm{~m} ; V=0.159 \mathrm{~m}^{3}$. Tests 


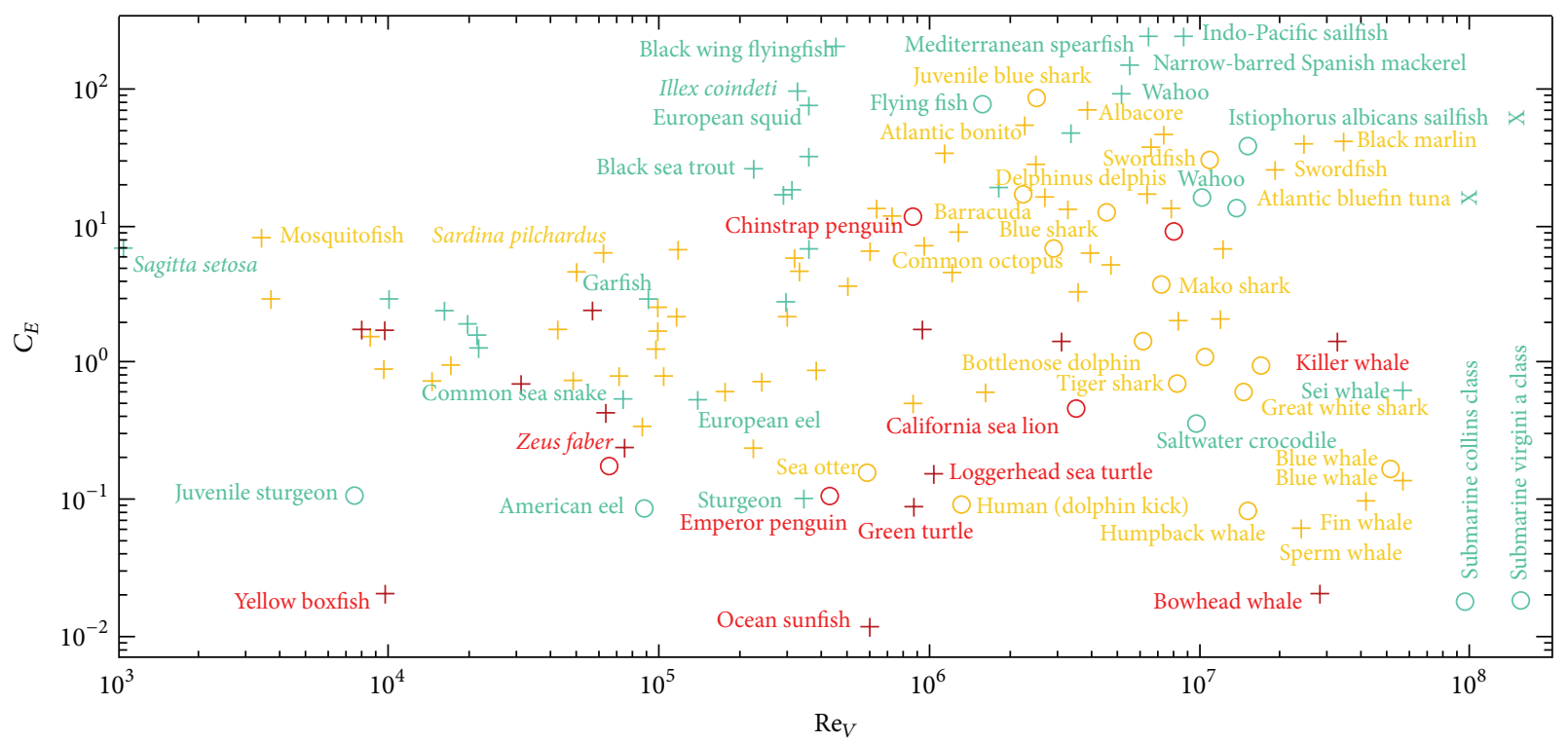

FIGURE 4: The capacity-efficiency factor $C_{E}(\mathrm{~W} / \mathrm{kg})$ versus volumetric Reynolds number for different animals and vehicles.

revealed the minimal value of $C_{V}=0.008$ at $R_{V}=0.85 \cdot 10^{7}$; (5) yields $C_{V}=0.0016$. The more slender body of Hansen and Hoyt [17] $(L / D=4.5 ; L=3.18 \mathrm{~m} ; D=0.71 \mathrm{~m})$ has the minimum experimental drag coefficient $C_{V}=0.007$ at $R_{V}=2.2 \cdot 10^{6}$ that is closer to the theoretical value $C_{V}=$ 0.0032 , which can be calculated from (5). The optimal shape $X-25(L / D=4.85)$ for an unclosed (tail-boom) body of revolution calculated in Parsons et al. [18] has $C_{V} \approx 0.005$ at $6 \cdot 10^{6}<R_{V}<1.6 \cdot 10^{7}$. For the same Reynolds number range the theoretical values of the minimum drag coefficient are $0.0012<C_{V}<0.0019$ (see (5)). The higher vales of the drag can be explained by the presence of separation and turbulence on all the above-mentioned bodies of revolution.

The theoretical drag values of different bodies of revolution calculated in Parsons et al. [18], Dodbele et al. [19], Zedan et al. [20], and Lutz and Wagner [21] are rather different. This can probably be explained as due to different semiempirical criteria for the laminar-turbulent transition in the boundary layer. The values of $C_{V}$ calculated in Parsons et al. [18], Dodbele et al. [19], Zedan et al. [20], and Lutz and Wagner [21] exceed estimation (5). For example, in Zedan et al. [20] the theoretical value $C_{V}=0.012$ at $R_{V}=1.5 \cdot 10^{7}$ was obtained, whereas the shape calculated by Parsons et al. [18] has 2.4 times less drag and (5) yields a ten times smaller value.

A similar comparison can be performed for the critical values of the Reynolds number calculations (12); for the bodies Dolphin, Hansen and Hoyt, and X-35 the critical Reynolds numbers are $R_{V}^{*} \approx 2.1 \cdot 10^{6}, R_{V}^{*} \approx 3.1 \cdot 10^{6}$, and $R_{V}^{*} \approx$ $3.4 \cdot 10^{6}$, respectively. At $10^{6}<R_{V}<1.6 \cdot 10^{7}$ the predictions of the laminar-to-turbulent transition coordinate presented by Parsons et al. [18] are approximately $0.5 \mathrm{~L}$ and $0.7 \mathrm{~L}$ for bodies Dolphin and $X-35$, respectively. This very slight dependence on the Reynolds number can be explained by the use of the cross-section of the laminar separation as the transition point in Parsons et al. [18], whereas (12) are obtained for shapes without any separation.
Expressions $(12)$ yield $R_{L}^{*} \approx 1.7 \cdot 10^{7}$ or $R_{V}^{*} \approx 3.8 \cdot 10^{6}$ for the bottlenose dolphin with body ratio $L / D=5.2$. These estimations resolve the well-known Gray paradox, since the Reynolds number $R_{L} \approx 1.4 \cdot 10^{7}$ taken for estimations in Gray [22] corresponds to laminar flow on the dolphin (see also [9]).

Thus slender bodies of revolution can delay laminarturbulent transitions on their surfaces and reduced skinfriction drag. It must be stressed that relations (12) are valid only for a flow pattern without separation. That is why the effect of the turbulization delay has not been achieved on standard (separated) slender bodies of revolution. The difference in shape can be hardly perceptible (see, e.g., Figure 5), but the pressure distribution is very sensitive to small changes in shape and similar shapes can have very different pressure gradients and separation behaviour. In particular, the body shape UA-2c has $L / D=3.6$, a negative-pressure-gradient forebody ending at the minimum pressure point $x \approx 0.33$, a long positive-pressure-gradient region (approximately $45 \%$ of the total body length), and a negative-pressure-gradient near its tail. Separation on Goldschmied's body $D=0.508 \mathrm{~m}$, $L / D=2.9$, with a long negative-pressure-gradient forebody (appox. 76\% of the total hull length), a short zone of pressure increase (its length $d \approx 10 \%$ ), and a negative-pressuregradient region near the tail, was removed only with the use of boundary layer suction; see Goldschmied [23].

4.2. Ranking of Different Animals and Vehicles. It can be seen from Figure 4 and Tables 1 and 2 that the best swimmers are fish whose shape corresponds to the minimal possible values of $C_{V}$. These are the Indo-Pacific sailfish, Mediterranean spearfish, narrow-barred Spanish mackerel, and wahoo. Some flying fish and some molluscs (e.g., southern shortfin squid Illex coindetii, European squid Loligo vulgaris) have similar values of $C_{E}$. These animals are both perfect swimmers and rather good fliers. In particular, the 
TABLE 1: The volumetric Reynolds number $R_{V}$ and the capacityefficiency factor $C_{E}(\mathrm{~W} / \mathrm{kg})$ for different animals based on formula (15) and data from Aleyev [6].

\begin{tabular}{|c|c|c|}
\hline Name & $\mathrm{Re}_{V}$ & $C_{E}(\mathrm{~W} / \mathrm{kg})$ \\
\hline Sagitta setosa & $1.0 * 10^{3}$ & 6.74 \\
\hline Gambusia affinis holbrooki & $3.4 * 10^{3}$ & 8.32 \\
\hline Lebistes reticulatus & $3.8 * 10^{3}$ & 2.92 \\
\hline Xiphophorus maculatus & $8.0 * 10^{3}$ & 1.74 \\
\hline Leucaspius delineatus & $8.6 * 10^{3}$ & 1.56 \\
\hline Mollienisia velifera & $9.6 * 10^{3}$ & 1.76 \\
\hline Ostracion tuberculatus & $9.7 * 10^{3}$ & 0.022 \\
\hline Clupeonella delicatula delicatula & $9.8 * 10^{3}$ & 0.887 \\
\hline Gymnammodytes cicerellus & $1.0 * 10^{4}$ & 2.97 \\
\hline Gasterosteusaculeatus & $1.4 * 10^{4}$ & 0.722 \\
\hline Atherina bonapartei & $1.6 * 10^{4}$ & 2.43 \\
\hline Xiphophorus helleru & $1.7 * 10^{4}$ & 0.924 \\
\hline Sprattus sprattus phalericus & $1.9 * 10^{4}$ & 1.91 \\
\hline Atherina mochon pontica & $2.2 * 10^{4}$ & 1.54 \\
\hline Atherina hepsetus & $2.2 * 10^{4}$ & 1.34 \\
\hline Chaetodon striatus & $3.1 * 10^{4}$ & 0.679 \\
\hline Alosa caspia nordmanni & $4.3 * 10^{4}$ & 1.81 \\
\hline Spicara smaris & $4.9 * 10^{4}$ & 0.730 \\
\hline Engraulis encrasicholus ponticus & $4.9 * 10^{4}$ & 4.83 \\
\hline Carassius auratis & $5.7 * 10^{4}$ & 2.49 \\
\hline Sardina pilchardus & $6.1 * 10^{4}$ & 6.24 \\
\hline Carassius carassius & $6.3 * 10^{4}$ & 0.482 \\
\hline Scardinius erythrophthalmus & $7.0 * 10^{4}$ & 0.831 \\
\hline Enhybrina schistosa & $7.1 * 10^{4}$ & 0.615 \\
\hline Zeus faber pungio & $7.5 * 10^{4}$ & 0.243 \\
\hline Labrus viridis & $8.7 * 10^{4}$ & 0.356 \\
\hline Belone belone euxini & $9.0 * 10^{4}$ & 2.95 \\
\hline Perca fluviatilis & $9.7 * 10^{4}$ & 1.33 \\
\hline Alosa kessleri pontica & $9.8 * 10^{4}$ & 1.74 \\
\hline Serranus scriba & $1.0 * 10^{5}$ & 2.61 \\
\hline Sciaena umbra & $1.0 * 10^{5}$ & 0.804 \\
\hline Rutilus rutilus & $1.1 * 10^{5}$ & 2.29 \\
\hline Clupea harengus pallasi & $1.1 * 10^{5}$ & 2.14 \\
\hline Leuciscus leuciscus & $1.1 * 10^{5}$ & 6.83 \\
\hline Anguilla anguilla & $1.4 * 10^{5}$ & 0.504 \\
\hline Odontogadus merlangus euxinus & $1.7 * 10^{5}$ & 0.617 \\
\hline Abramis brama & $2.3 * 10^{5}$ & 0.245 \\
\hline Salmo trutta labrax m. fario & $2.3 * 10^{5}$ & 25.7 \\
\hline Cyprinus carpio carpio & $2.4 * 10^{5}$ & 0.725 \\
\hline Sphyraena sphyraena & $2.9 * 10^{5}$ & 17.2 \\
\hline Trichiurus lepturus & $2.9 * 10^{5}$ & 2.69 \\
\hline Umbrina cirrosa & $2.9 * 10^{5}$ & 2.19 \\
\hline Todarodes pacificus & $3.1 * 10^{5}$ & 18.8 \\
\hline Mugil saliens & $3.2 * 10^{5}$ & 5.71 \\
\hline Ilex coindeti & $3.2 * 10^{5}$ & 96.6 \\
\hline Acipenserstellatus & $3.2 * 10^{5}$ & 0.117 \\
\hline Mugil auratus & $3.3 * 10^{5}$ & 4.70 \\
\hline Loligo vulgaris & $3.6 * 10^{5}$ & 77.9 \\
\hline Todarodes sagittatus & $3.6 * 10^{5}$ & 7.05 \\
\hline
\end{tabular}

TABle 1: Continued.

\begin{tabular}{|c|c|c|}
\hline Name & $\mathrm{Re}_{V}$ & $C_{E}(\mathrm{~W} / \mathrm{kg})$ \\
\hline Symplectoteuthis oualaniensis & $3.6 * 10^{5}$ & 9.20 \\
\hline Loligo forbesi & $3.6 * 10^{5}$ & 31.3 \\
\hline Gadus morhua macrocephalus & $3.8 * 10^{5}$ & 0.855 \\
\hline Hirundichthys rondeletii & $4.5 * 10^{5}$ & 202.4 \\
\hline Stizostedion lucioperca & $4.9 * 10^{5}$ & 3.85 \\
\hline Mola mola & $6.0 * 10^{5}$ & 0.0112 \\
\hline Salmo trutta & $6.1 * 10^{5}$ & 6.52 \\
\hline Scomber scombrus & $6.4 * 10^{5}$ & 13.2 \\
\hline Trachurus mediterraneus ponticus & $7.2 * 10^{5}$ & 11.4 \\
\hline Squalus acanthias & $7.5 * 10^{5}$ & 1.18 \\
\hline Acipenser gueldenstaedtiicolchicus & $8.8 * 10^{5}$ & 0.505 \\
\hline Chelonia mydas & $9.0 * 10^{5}$ & 0.0877 \\
\hline Eretmochelys imbricata & $9.5 * 10^{5}$ & 1.77 \\
\hline Mugil cephalus & $9.6 * 10^{5}$ & 6.95 \\
\hline Caretta caretta & $1.0 * 10^{6}$ & 0.160 \\
\hline Auxis thazard & $1.1 * 10^{6}$ & 36.1 \\
\hline Pomatomus saltatrix & $1.2 * 10^{6}$ & 5.14 \\
\hline Pygoscelis adeliae & $1.3 * 10^{6}$ & 9.65 \\
\hline Eudyptes chrysolophus & $1.3 * 10^{6}$ & 9.45 \\
\hline Huso huso & $1.6 * 10^{6}$ & 0.633 \\
\hline Esox lucius & $1.8 * 10^{6}$ & 18.8 \\
\hline Sarda sarda & $2.3 * 10^{6}$ & 52.4 \\
\hline Salmo trutta labrax & $2.5 * 10^{6}$ & 29.3 \\
\hline Salmo salar & $2.6 * 10^{6}$ & 16.2 \\
\hline Phoca groenlandica & $2.9 * 10^{6}$ & 1.43 \\
\hline Dermochelys coriacea & $3.1 * 10^{6}$ & 1.44 \\
\hline Phocoena phocoena & $3.3 * 10^{6}$ & 12.4 \\
\hline Sphyraena barracuda & $3.4 * 10^{6}$ & 45.8 \\
\hline Arctocephalus pusillus & $3.5 * 10^{6}$ & 3.21 \\
\hline Thunnus alalunga & $3.9 * 10^{6}$ & 70.6 \\
\hline Sphyrna zygaena & $3.9 * 10^{6}$ & 6.79 \\
\hline Stenopterygius quadriscissus & $4.6 * 10^{6}$ & 5.20 \\
\hline Acanthocybium solandri & $5.1 * 10^{6}$ & 90.7 \\
\hline Scomberomorus commerson & $5.6 * 10^{6}$ & 150.8 \\
\hline Delphinus delphis ponticus & $6.3 * 10^{6}$ & 16.9 \\
\hline Tetrapturus belone & $6.4 * 10^{6}$ & 244.5 \\
\hline Coryphaena hippurus & $6.7 * 10^{6}$ & 37.4 \\
\hline Thunnus albacares & $7.3 * 10^{6}$ & 47.9 \\
\hline Thunnus obesus & $7.9 * 10^{6}$ & 13.0 \\
\hline Prionace glauca & $8.2 * 10^{6}$ & 2.15 \\
\hline Istiophorus platypterus & $8.8 * 10^{6}$ & 246.5 \\
\hline Globicephala melas & $1.2 * 10^{7}$ & 2.05 \\
\hline Tursiops truncatus & $1.2 * 10^{7}$ & 6.80 \\
\hline Thunnus thynnus & $1.9 * 10^{7}$ & 24.9 \\
\hline Xiphias gladius & $2.4 * 10^{7}$ & 39.6 \\
\hline Physeter catodon & $2.4 * 10^{7}$ & 0.0604 \\
\hline Balaena mysticetus & $2.8 * 10^{7}$ & 0.0220 \\
\hline Orcinus orca & $3.3 * 10^{7}$ & 1.41 \\
\hline Makaira indica & $3.4 * 10^{7}$ & 41.7 \\
\hline Balaenoptera physalus & $4.1 * 10^{7}$ & 0.0973 \\
\hline Balaenoptera borealis & $5.6 * 10^{7}$ & 0.618 \\
\hline Balaenoptera musculus & $5.7 * 10^{7}$ & 0.129 \\
\hline
\end{tabular}


TABLE 2: The volumetric Reynolds number $R_{V}$ and the capacity-efficiency factor $C_{E}(\mathrm{~W} / \mathrm{kg})$ for different animals and submarines based on formula (15) and the maximum velocity, mass, and viscosity data. The following sources of the primal information were used: Dickson et al. [27] for Green jack Caranx caballus; Deslauriers and Kieffer [28] for juvenile Shortnose sturgeon Acipenser brevirostrum; other primal data about maximum velocity $U_{m}$, the mass $m$, and the water kinematic viscosity coefficient $\nu$ is added by authors with the use of the Internet (e.g., http://www.speedofanimals.com/animals/bottlenose_dolphin).

\begin{tabular}{|c|c|c|c|c|c|}
\hline \multirow{2}{*}{ Name } & \multirow{2}{*}{$\operatorname{Re}_{V}$} & \multirow{2}{*}{$C_{E}(\mathrm{~W} / \mathrm{kg})$} & \multicolumn{3}{|c|}{ Primal information } \\
\hline & & & $U_{m}(\mathrm{~m} / \mathrm{s})$ & $m(\mathrm{Kg})$ & $v \cdot 10^{6}\left(\mathrm{~m}^{2} / \mathrm{s}\right)$ \\
\hline Acipenser brevirostrum & $7.4 * 10^{3}$ & 0.0998 & 0.45 & 0.0156 & 1.52 \\
\hline Caranx caballus & $6.6 * 10^{4}$ & 0.174 & 1.03 & 0.19 & 0.90 \\
\hline Anguilla rostrata & $8.8 * 10^{4}$ & 0.0872 & 1.08 & 1.5 & 1.40 \\
\hline Aptenodytes forsteri & $3.8 * 10^{5}$ & 0.105 & 2.08 & 35.0 & 1.80 \\
\hline Enhydra lutris & $6.0 * 10^{5}$ & 0.153 & 2.50 & 30.0 & 1.30 \\
\hline Pygoscelis antarcticus & $8.7 * 10^{5}$ & 11.0 & 8.97 & 4.5 & 1.70 \\
\hline Human (sportsmen dolphin kick) & $1.3 * 10^{6}$ & 0.0946 & 2.70 & 80.0 & 0.90 \\
\hline Cypselurus californicus & $1.6 * 10^{6}$ & 72.6 & 15.69 & 1.0 & 1.00 \\
\hline Sphyraena argentea & $2.2 * 10^{6}$ & 17.3 & 12.20 & 4.5 & 0.90 \\
\hline Prionace glauca (juvenile) & $2.4 * 10^{6}$ & 83.2 & 19.20 & 2.0 & 1.00 \\
\hline Octopus vulgaris & $2.9 * 10^{6}$ & 7.41 & 11.10 & 17.0 & 1.00 \\
\hline Zalophus californianus & $3.5 * 10^{6}$ & 0.464 & 6.00 & 200.0 & 1.00 \\
\hline Prionace glauca (adult) & $4.6 * 10^{6}$ & 12.3 & 10.9 & 75.2 & 1.00 \\
\hline Tursiops truncatus & $6.1 * 10^{6}$ & 1.39 & 9.72 & 250.0 & 1.00 \\
\hline Isurus oxyrinchus & $7.2 * 10^{6}$ & 3.53 & 3.90 & 300.0 & 1.30 \\
\hline Thunnus orientalis & $8.0 * 10^{6}$ & 9.62 & 19.40 & 250.0 & 1.52 \\
\hline Galeocerdo cuvier & $8.1 * 10^{6}$ & 0.710 & 8.89 & 550.0 & 0.90 \\
\hline Crocodylus porosus & $9.8 * 10^{6}$ & 0.357 & 7.80 & 1000.0 & 0.80 \\
\hline Acanthocybium solandri & $1.0 * 10^{7}$ & 16.7 & 21.40 & 80.0 & 0.90 \\
\hline Carcharodon carcharias & $1.0 * 10^{7}$ & 1.082 & 11.11 & 800.0 & 1.00 \\
\hline Xiphias gladius & $1.1 * 10^{7}$ & 30.3 & 26.90 & 98.0 & 1.15 \\
\hline Tetrapturus audax & $1.4 * 10^{7}$ & 13.3 & 22.50 & 163.0 & 0.90 \\
\hline Carcharodon carcharias & $1.5 * 10^{7}$ & 0.557 & 11.11 & 3324.0 & 1.10 \\
\hline Istiophorus albicans & $1.5 * 10^{7}$ & 38.4 & 30.56 & 90.0 & 0.90 \\
\hline Megaptera novaeangliae & $1.6 * 10^{7}$ & 0.0810 & 7.50 & $3.0 * 10^{4}$ & 1.50 \\
\hline Orcinus orca & $1.7 * 10^{7}$ & 0.875 & 13.42 & $4.1 * 10^{5}$ & 1.30 \\
\hline Balaenoptera musculus & $5.1 * 10^{7}$ & 0.160 & 13.90 & $1.7 * 10^{5}$ & 1.52 \\
\hline Submarine Collins class (diesel) & $1.25 * 10^{8}$ & 0.0190 & 10.83 & $3.353 * 10^{6}$ & 1.30 \\
\hline Submarine Virginia class (nuclear) & $1.96 * 10^{8}$ & 0.0183 & 12.78 & $7.9 * 10^{6}$ & 1.30 \\
\hline
\end{tabular}

squid change their shape during flight to create lift forces (see, e.g., $[24])$.

The capacity-efficiency factor of the best swimmers is approximately 100 times greater than that of common good swimmers. For example, burst swimming corresponds to values of circa 10 body lengths per second for subcarangiform fish of between 10 and $20 \mathrm{~cm}$ in length [25]. Applying expressions (11) and (15) and the average value $v=1.3$. $10^{-6} \mathrm{~m}^{2} / \mathrm{s}$ yields

$$
C_{E} \approx 1.56 L \frac{L}{D}(\mathrm{~W} / \mathrm{kg}),
$$

where $L$ must be taken in metres. For the largest fish of $L=$ $0.2 \mathrm{~m}$ and $D / L=0.1$ the value of $C_{E}$ is $3.1 \mathrm{~W} / \mathrm{kg}$. According to the data of Azuma [26] the capacity per unit of body mass varies from 10 to $160 \mathrm{~W} / \mathrm{kg}$.

The smallest values of $C_{E}$ are associated with nonstreamlined animals (e.g., ocean sunfish Mola mola, yellow boxfish
Ostracion tuberculatus, bowhead whale Balaena mysticetus, or sperm whale Physeter catodon) and submarines. The shapes of these animals and vehicles obviously cannot ensure any attached flow pattern. The low values of $C_{E}$ for submarines are both the result of the large supercritical Reynolds numbers at which they move (there are huge differences in the theoretical values of both the laminar and the turbulent friction, shown in Figure 3) and of the separation that increases the drag 3to 5 -fold in comparison to the value possible for an attached flow pattern.

Whales have a rather wide range of values of $C_{E}$, larger for the hydrodynamically "better shaped" animals; for example, the sei whale Balaenoptera borealis has approximately 10 times greater capacity-efficiency factor than the bowhead whale Balaena mysticetus. The main predator of whales-the killer whale Orcinus orca-has approximately twice as large a value of $C_{E}$ as the sei whale and comes close to the characteristics of its relative, the bottlenose dolphin Tursiops truncatus. 


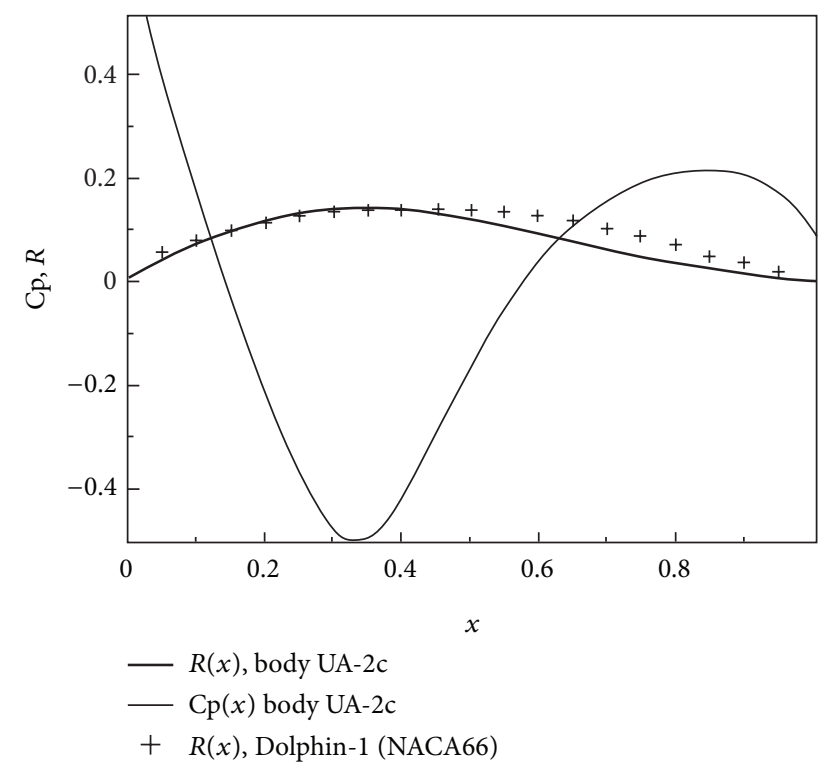

FIGURE 5: Comparison of the special shaped unseparated body of revolution UA-2c [8] with the "Dolphin-1" body based on NACA66 profile.

Humans are not the best swimmers. For example, the world records men have a $C_{E}$ value similar to some turtles, sturgeons, and the blue whale Balaenoptera musculus, 2000 times smaller than the capacity-efficiency of the best swimmers.

The sharks have a very broad range of capacity-efficiency factor that decreases with increasing Reynolds number. For example, the juvenile blue shark belongs to the best swimmers, while barracuda and adult blue shark have 7-9 times smaller values of $C_{E}$. The largest great white sharks that swim at supercritical Reynolds numbers have the smallest value of $C_{E}$. The same large difference can be seen in the case of birds. For example, the small and fast chinstrap penguin Pygoscelis antarcticus has approximately 100 times greater value of $C_{E}$ than the large and slow emperor penguin Aptenodytes forsteri.

The capacity-efficiency factor can be sometimes very close for juvenile and adult animals (e.g., sturgeon) and sometimes very different (e.g., blue shark). In the case of the blue shark the large difference can be explained by the fact that juvenile animals swim at subcritical Reynolds number, whereas the adults swim at transitional and supercritical values of $R_{V}$.

4.3. Final Remarks. It can be concluded that the best swimmers have a streamlined shape that ensures an attached flow pattern and a laminar boundary layer at rather large values of the Reynolds number. As a result the hydrodynamical drag can be much smaller in comparison with the "poorly" shaped animals and vehicles where separation and/or turbulence occur.

The large difference in corresponding $C_{E}$ values (see Figure 5 and Tables 1 and 2) shows that information about animal shapes and locomotion is not only of biological interest but very useful to improve the capabilities of robot fish and underwater vehicles as well. Better measurements of the maximum velocity, mass, and water temperature are necessary to determine the top swimmers among the animals.

The volumetric drag coefficient of an ideal laminar unseparated body of revolution with a prescribed volume is independent of the shape and can be calculated from expression (5), which can be a rather good estimate of the drag on the best-shaped fish. The critical value of the Reynolds number depends on the shape peculiarities and increases as the slenderness ratio $D / L$ decreases (see (12)). At supercritical Reynolds numbers a turbulent boundary layer develops along the body's tail and the drag increases drastically.

The capacity-efficiency factor (15) can be used to estimate the swimming efficiency of both animals and underwater vehicles. Animals that swim at supercritical Reynolds numbers have much smaller value of $C_{E}$ in comparison with the best swimmers at subcritical values of $R_{V}$.

\section{Conflict of Interests}

The authors declare that there is no conflict of interests regarding the publication of this paper.

\section{Acknowledgments}

The authors thank Julyan Cartwright for very useful discussions of the results and his assistance in preparing the paper. The study was supported by the EU-financed Project EUMLS (EU-Ukrainian Mathematicians for Life Sciences) Grant agreement PIRSES-GA-2011-295164-EUMLS.

\section{References}

[1] R. W. Blake, "Fish functional design and swimming performance," Journal of Fish Biology, vol. 65, no. 5, pp. 1193-1222, 2004.

[2] C. M. Breder, "The locomotion of fishes," Zoologica, vol. 4, pp. 159-297, 1926.

[3] C. C. Lindsey, "Form, function and locomotory habits in fish," in Fish Physiology, W. S. Hoar and D. J. Randall, Eds., vol. 7, pp. 1-100, Academic Press, London, UK, 1978.

[4] P. W. Webb and R. W. Blake, "Swimming," in Functional Vertebrate Morphology, M. Hildebrand, D. M. Bramble, K. F. Liem, and D. B. Wake, Eds., pp. 111-128, Belknap Press, Cambridge, Mass, USA, 1985.

[5] L. G. Loitsyanskiy, in Mechanics of Liquids and Gases, Begell House, New York, NY, USA, 6th edition, 1995.

[6] Y. G. Aleyev, Nekton, Dr. W. Junk, The Hague, The Netherlands, 1977.

[7] J. Rohr, M. I. Latz, S. Fallon, J. C. Nauen, and E. Hendricks, "Experimental approaches towards interpreting dolphinstimulated bioluminescence," Journal of Experimental Biology, vol. 201, no. 9, pp. 1447-1460, 1998.

[8] I. Nesteruk, "New type of unseparated subsonic shape of axisymmetric body," Reports of the National Academy of Sciences of Ukraine, vol. 11, pp. 49-56, 2003 (Ukrainian).

[9] I. Nesteruk and J. H. E. Cartwright, "Turbulent skin-friction drag on a slender body of revolution and Gray's paradox," Journal of Physics, vol. 318, no. 2, Article ID 022042, 2011. 
[10] J. D. Cole, Perturbation Methods in Applied Mathematics, Blaisdell, London, UK, 1968.

[11] I. Nesteruk, "Reserves of the hydrodynamical drag reduction for axisymmetric bodies., Bulletin of Kiev University, no. 1, pp. 112118, 2002.

[12] L. D. Landau and E. M. Lifshits, Fluid Mechanics, vol. 6 of Course of Theoretical Physics, Butterworth-Heinemann, Oxford, UK, 2nd edition, 1987.

[13] I. Nesteruk, "Peculiarities of turbulization and separation of boundary-layer on slender axisymmetric subsonic bodies," Naukovi Visti, NTUU, vol. 3, pp. 70-76, 2002 (Ukrainian).

[14] K. Yanase and T. Arimoto, "A hydro-mechanical approach to the scaling of swimming performance in the sand flathead Platycephalus bassensis Cuvier: effects of changes in morphological features based on fish size," Journal of Fish Biology, vol. 71, no. 6, pp. 1751-1772, 2007.

[15] S. F. Hoerner, Fluid-Dynamic Drag, Hoerner, Midland Park, NJ, USA, 1965.

[16] L. Greiner, Editor, Underwater Missile Propulsion, Compass Publications, La Jolla, Calif, USA, 1967.

[17] R. J. Hansen and J. G. Hoyt, "Laminar-to-turbulent transition on a body of revolution with an extended favorable pressure gradient forebody," Journal of Fluids Engineering, vol. 106, no. 2, pp. 202-210, 1984.

[18] J. S. Parsons, R. E. Goodson, and F. R. Goldschmied, "Shaping of axisymmetric bodies for minimum drag in incompressible flow," Journal of Hydronautics, vol. 8, no. 3, pp. 100-107, 1974.

[19] S. S. Dodbele, C. P. Van Dam, P. M. H. W. Vijgen, and B. J. Holmes, "Shaping of airplane fuselages for minimum drag," Journal of Aircraft, vol. 24, no. 5, pp. 298-304, 1987.

[20] M. F. Zedan, A. A. Seif, and S. Al-Moufadi, "Drag reduction of airplane fuselages through shaping by the inverse method," Journal of Aircraft, vol. 31, no. 2, pp. 279-287, 1994.

[21] T. Lutz and S. Wagner, "Drag reduction and shape optimization of airship bodies," Journal of Aircraft, vol. 35, no. 3, pp. 345-351, 1998.

[22] J. Gray, "Studies in animal locomotion VI. The propulsive powers of the dolphin," Journal of Experimental Biology, vol. 13, pp. 192-199, 1936.

[23] F. R. Goldschmied, "Integrated hull design, boundary layer control and propulsion of submerged bodies: wind tunnel verification," in Proceedings of the AIAA/SAE/ASME 18th Joint Propulsion Conference, AIAA paper 82-1204, pp. 3-18, 1982.

[24] K. Muramatsu, J. Yamamoto, T. Abe, K. Sekiguchi, N. Hoshi, and Y. Sakurai, "Oceanic squid do fly," Marine Biology, vol. 160, no. 5, pp. 1171-1175, 2013.

[25] R. Bainbridge, "Speed and stamina in three fish," Journal of Experimental Biology, vol. 37, pp. 129-153, 1960.

[26] A. Azuma, The Biokinetics of Flying and Swimming, Springer, Tokyo, Japan, 1992.

[27] K. A. Dickson, J. M. Donley, M. W. Hansen, and J. A. Peters, "Maximum sustainable speed, energetics and swimming kinematics of a tropical carangid fish, the green jack Caranx caballus," Journal of Fish Biology, vol. 80, pp. 2494-22516, 2012.

[28] D. Deslauriers and J. D. Kieffer, "The effects of temperature on swimming performance of juvenile shortnose sturgeon (Acipenser brevirostrum)," Journal of Applied Ichthyology, vol. 28, no. 2, pp. 176-181, 2012. 

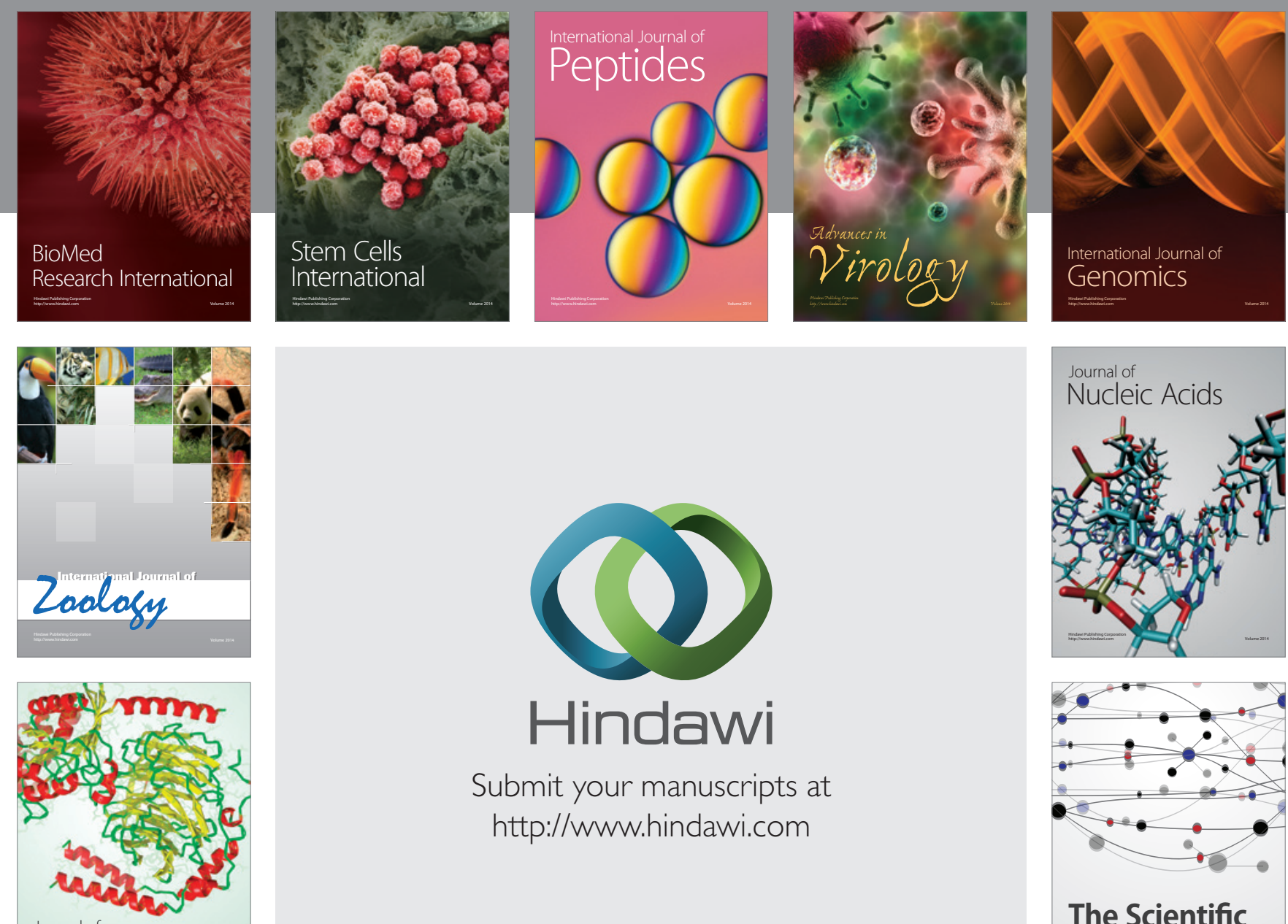

Submit your manuscripts at

http://www.hindawi.com

Journal of
Signal Transduction
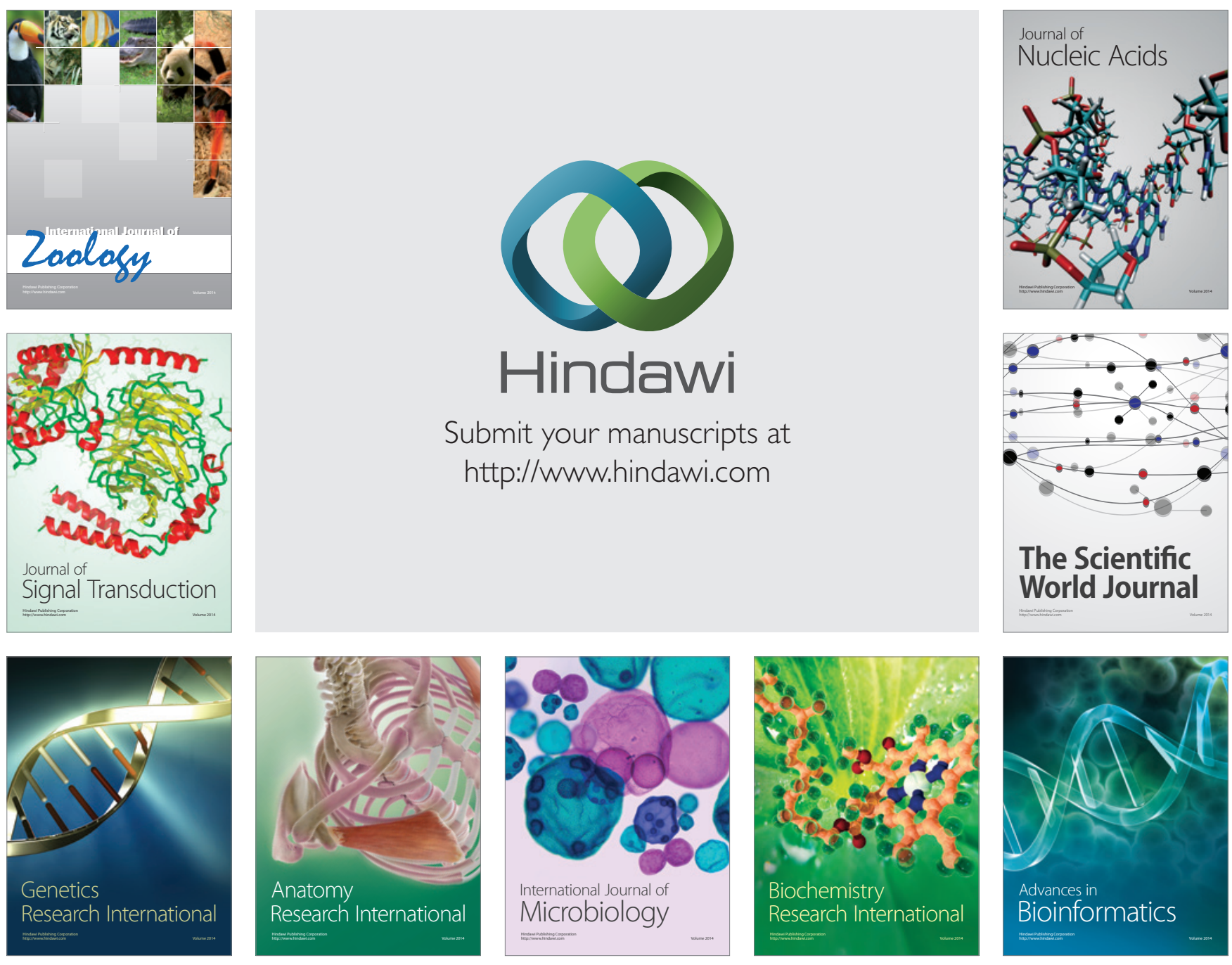

The Scientific World Journal
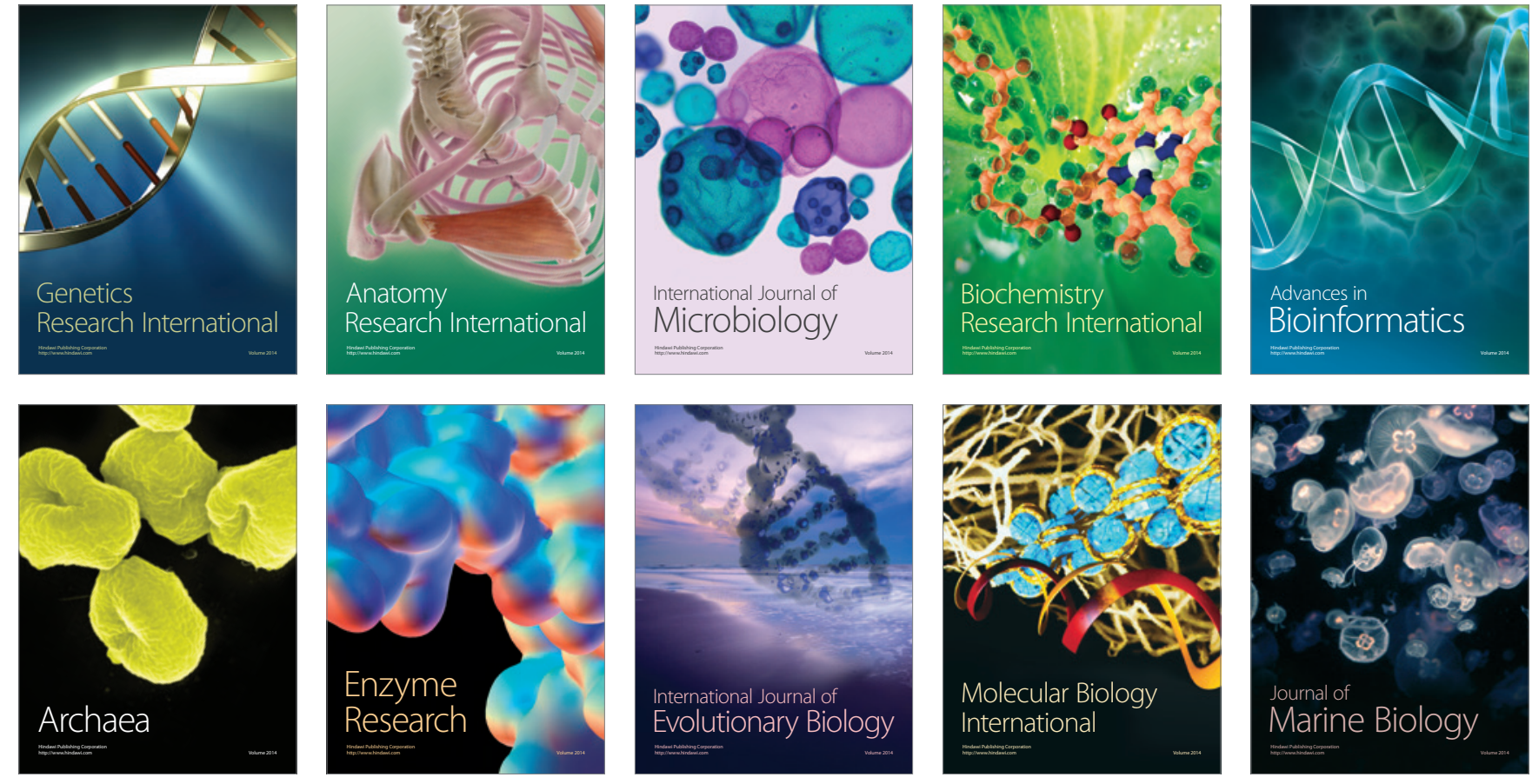